\title{
Teenager with multiple fractures
}

Peter Kei Tat Hui • Joanna Y. L. Tung •

Wendy W. M. Lam • M. T. Chau

Received: 21 February 2011 /Revised: 31 May 2011 / Accepted: 4 July 2011 /Published online: 27 July 2011

(C) ISS 2011

\section{History}

A 16-year-old boy presented with recurrent fractures of the long bones and spine since the age of 7 months (Figs. 1 and 2).

Fig. 1 Lateral radiograph of right forearm

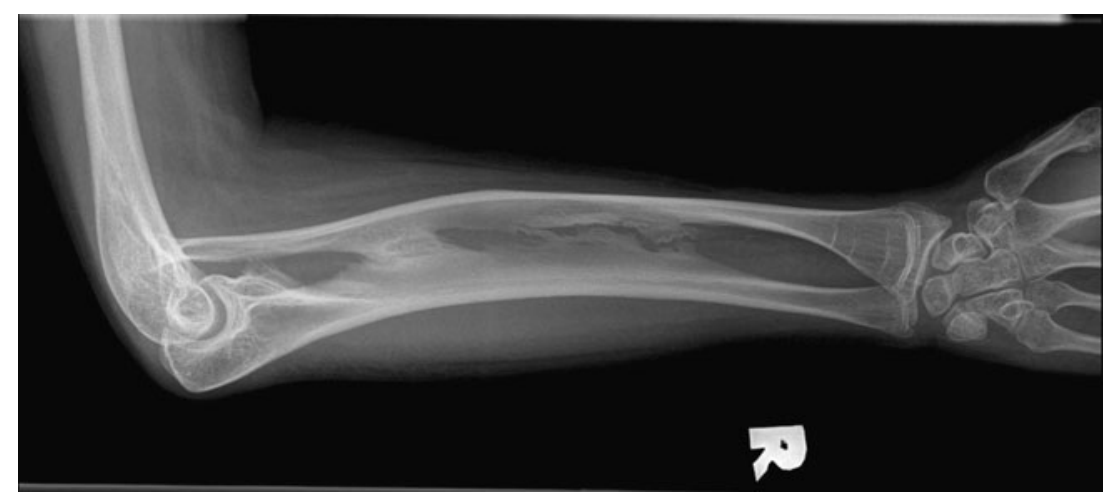

The diagnosis can be found at doi:10.1007/s00256-011-1236-x.

P. K. T. Hui $(\bowtie) \cdot$ W. W. M. Lam $\cdot$ M. T. Chau Department of Radiology, Queen Mary Hospital, 102 Pokfulam Road, Southern, HKSAR, China

e-mail: peterkthui@gmail.com

J. Y. L. Tung

Department of Paediatrics and Adolescent Medicine, Queen Mary Hospital, The University of Hong Kong, HKSAR, China

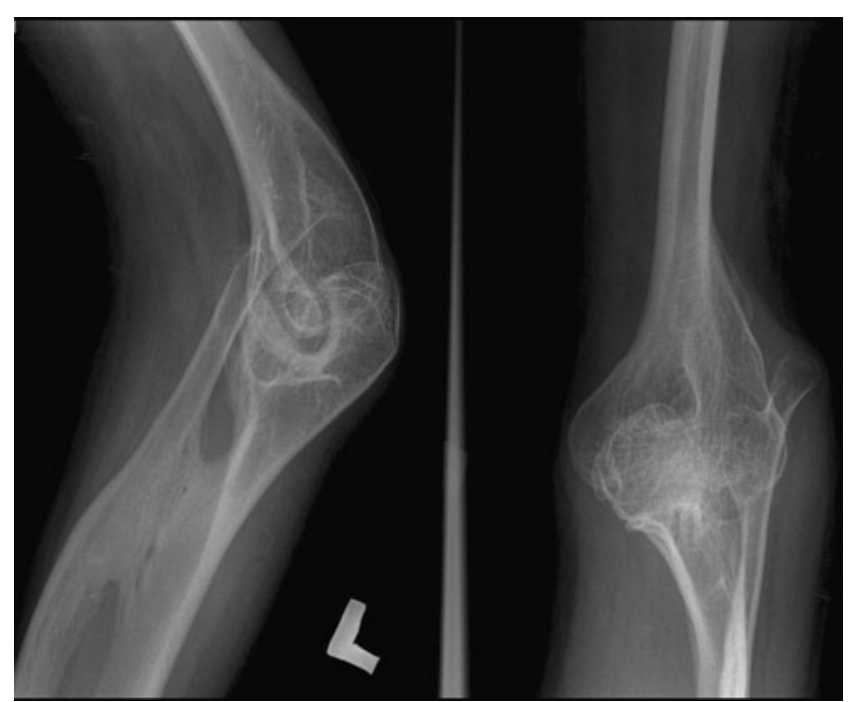

Fig. 2 Frontal and lateral radiograph of left elbow 